\title{
Transcription profile of a human breast cancer cell line expressing MMTV-like sequences \\ Mariana Fernandez-Cobo ${ }^{1}$, Stella M Melana ${ }^{1}$, James F Holland ${ }^{1}$ and Beatriz GT Pogo*1,2
}

Address: ${ }^{1}$ Department of Medicine, Mount Sinai School of Medicine, New York, USA and ${ }^{2}$ Department of Microbiology, Mount Sinai School of Medicine, New York, USA

Email: Mariana Fernandez-Cobo - mariana.fernandez@mssm.edu; Stella M Melana - stella.melana@mssm.edu; James F Holland - james.holland@mssm.edu; Beatriz GT Pogo* - beatriz.pogo@mssm.edu

* Corresponding author

Published: 15 December 2006

Infectious Agents and Cancer 2006, I:7 doi:10.1 I86/1750-9378-I-7
Received: 26 October 2006

Accepted: 15 December 2006

This article is available from: http://www.infectagentscancer.com/content/ // //7

(C) 2006 Fernandez-Cobo et al; licensee BioMed Central Ltd.

This is an Open Access article distributed under the terms of the Creative Commons Attribution License (http://creativecommons.org/licenses/by/2.0), which permits unrestricted use, distribution, and reproduction in any medium, provided the original work is properly cited.

\begin{abstract}
Background: It has been postulated that inflammation caused by certain viruses might result in cancer. Recently, it was shown that childhood lymphoblastic leukemia, breast and ovarian cancers express an interferon-related signature, providing support for this notion. We have previously shown that $38 \%$ of the sporadic breast cancers contain MMTV-like env gene sequences. To find out if the presence and expression of MMTV-like sequences correlated with an inflammatory phenotype, we have compared the expression profile of two sublines of MCF-7 cells, one containing the MMTV-like sequences (env+), the other one lacking them (env-).
\end{abstract}

Results: The results indicated that there were 47 differentially expressed genes between the two sublines. Among 27 upregulated genes in the env ${ }^{+}$cells there were 7 interferon-related genes, 5 TNF-connected genes and 2 TGF $\beta$-related genes.

Conclusion: These results suggest that the env+ cells were most likely responding to an infectious agent, and support the hypothesis that a viral infection may play a role in breast cancer pathogenesis.

\section{Background}

We and others [1-4] have shown that 37 to $41 \%$ of sporadic breast cancer samples contain MMTV-like env gene sequences. The sequences are expressed as RNA [5] and as protein in breast cancers (Melana et al., submitted). They are absent from the normal breasts of patients with env positive tumors [6] and are expressed as RNA exclusively in the cancer cells [7]. The whole proviral structure, designated human mammary tumor virus (HMTV), which has 95\% homology to MMTV, can be detected in two tumors [8]. Although sequence variations are observed in the C- terminal of human sag sequences, the cloned human sag sequences expressed in human B lymphocytes can activate human T-cells, as can the mouse Sag, indicating that it can be functional [9]. Moreover, viral particles with the morphological characteristics of betaretroviruses are observed in primary cultures of human beast cancer [10]. Taken together, these results suggest that an infectious agent is present in some human breast cancers.

Chronic inflammation has been implicated in tumor progression. New evidence suggests that the inflammation 
caused by certain viruses results in cancer [Reviewed in [11]]. Recently, it was reported that childhood lymphoblastic leukemia, as well as breast and ovarian cancers express an interferon-related signature, but not found in other human cancers studied [12]. This finding provides molecular support for the role of inflammation or viral infection in cancer pathogenesis [12].

The established breast cancer cell line MCF-7 is widely used in research, and many subclones are available. Some of the original isolates produce retroviral-like particles [13]. Furthermore, May and Westerly [14] described the presence of an MMTV-like 6.6 Kb EcoR1 fragment in some of the MCF-7 cell lines, which was absent in other breast cancer lines and in normal tissue.

Continuous passage with subsequent chromosomal change [15] may have eliminated viral sequences from some of them. It has been reported that some sublines of MCF-7 show biological differences [16] and significant genetic variation in RNA expression $[17,18]$.

We have previously reported that a subline of MCF-7 containing env and LTR sequences $[19,20]$ and that it expressed the env gene as RNA [7], while other sublines were negative for $e n v$ gene [[21] and our own results]. To find out whether the presence of viral sequences is related to an interferon-related signature, we have compared the expression profiles of two sublines of MCF-7 [22], one which contains the MMTV-like env gene sequence $(e n v+)$ and one which lacks it (env-).

\section{Results}

The presence of the Env protein was investigated in both sublines. In Fig. 1 the result of the immunoblotting experiment is shown. The HMTV env+ cell line expressed a protein of a MW of approximately $50 \mathrm{kD}$ which reacted with mAbP2, a monoclonal antibody against a synthetic peptide derived from human env sequences (Melana et al submitted). It was absent in the HMTV env-cells. Tubulin was equally present in both extracts.

The results of the cDNA arrays are shown in Tables 1 and 2. Nineteen genes showed a $>2.5$ fold difference in their adjusted intensity between HMTV env+ and $e n v$ - cells, while another eight genes were only expressed in the HMTV env+ cells (Table 1). Twenty genes were downregulated (Table 2) in HMTV env + cells. Taken together, there were 47 differentially expressed genes. Among the 27 upregulated genes there were six interferon-inducible ones: IFI6, TRIM22, IFITM1, IFITM2+IFITM3, IFI27 and IP-30 and a receptor IFNGR2. In addition, there were five upregulated genes that have a connection with TNF or are involved in its signaling, like LTBR, TRAF3, MMP17,

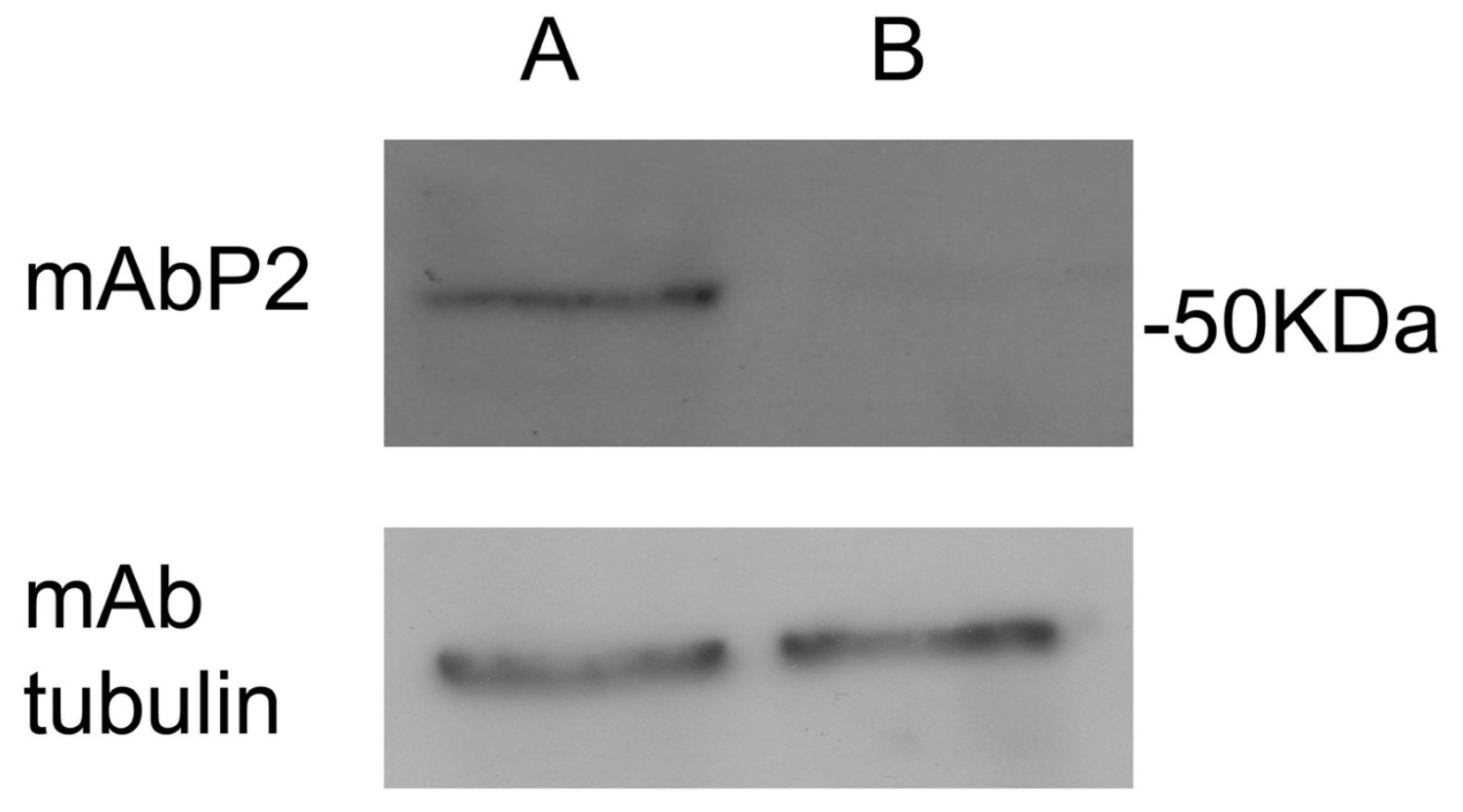

Figure I

Western blot of MCF-7 cells. Experimental conditions as described in Materials and Methods. A: MCF-7 (+) cells; B: MCF-7(-) cells. 
PKN1 and MAPK13. The cytokine TGF $\beta$, and its downstream effector early growth response protein 1 (EGR1), were also upregulated in $e n v+$ cells. Twenty genes were down regulated in HMTV env+ cells.

\section{Discussion}

Comparison of the expression profiles of sublines derived from the same cell line provides an excellent model with minimal differences. Karyogenetic analysis revealed that the two sublines have similar complex chromosomal patterns (not shown). The comparison of expression profiles of MCF-7 $e n v+$ and $e n v$ - cells indicated preferential expression of interferon-related genes: $26 \%$ (7/27) of the up-regulated genes. These differences may indicate a trend. Einav et al. [12] have reported that $40 \%$ of clinical breast cancer samples display an interferon-associated signature; 17 out of $36(47 \%)$ of the upregulated genes. Our results are consistent with, but cannot be directly compared with those of Einav's for several reasons: we used only one cell line for analysis, the participation of stroma and surrounding tissues has been eliminated from our study, and finally, we used a different set of arrays. Nevertheless, our results strongly indicate that HMTV env+ MCF-7 cells express more interferon-related genes than the HMTV env-MCF-7 cells, suggesting that they may be responding to an infectious agent as proposed by Einav et al. [12]. The expres- sion profile of HMTV env+ cells suggests an increased potential for cell growth, a fact that may be related to their more malignant phenotype as has been described in breast cancer cells associated with HMTV $[23,3,24]$. It is remarkable that the alpha 7 and beta 4 integrins were significantly down regulated in env+ cells, as has been reported in a set of finite life-span metastatic breast cancer cells which were also env+ [25].

Whether the HMTV works as initiator and/or as promoter of malignant growth is uncertain. Molecular evidence that HMTV expression is responsible for the increase in interferon-related expression is being sought.

\section{Conclusion}

The results clearly indicate that the transcriptional profile of the cells expressing HMTV sequences is enriched in genes involved in inflammation process. This finding is significant because it was obtained comparing cells derived from the same cell line that have similar genetic background and minimal expressing differences. This supports the hypothesis that a viral infection may play a role in breast cancer pathogenesis.

Table I: Up-regulated genes in HMTV env+ cells

\begin{tabular}{|c|c|c|c|c|}
\hline Acc \# & Gene symbol & Protein/gene & Ratio & Diff \\
\hline$\underline{X 02492}$ & IFI6 & Interferon-inducible protein 6 & 12.44 & 4108 \\
\hline J05633 & ITGB5 & Integrin beta 5 & 9.46 & 3401 \\
\hline$\underline{X 82200}$ & TRIM22 & Tripartite motif-containing 22 & 5.76 & 1495 \\
\hline$\underline{\mathrm{L} 03840}$ & FGFR4 & Fibroblast growth factor receptor 4 & 5.72 & 1742 \\
\hline 104164 & IFITMI & Interferon induced transmembrane protein I (9-27) & 5.38 & 6776 \\
\hline M64595 & & small G protein & 4.74 & 1720 \\
\hline$\underline{\times 57351}$ & IFITM2 + IFITM3 & interferon induced transmembrane prot $2(I-8 D)+3(I-8 U)$ & 4.25 & 1082 \\
\hline X89576 & MMPI7 & matrix metalloproteinase 17 & 4.20 & 1647 \\
\hline$\times 52541$ & EGRI & early growth response protein I & 3.39 & 1327 \\
\hline$\underline{\mathrm{L} 29220}$ & CLK3 & CDC-like kinase 3 & 3.38 & $|52|$ \\
\hline$\underline{X 66362}$ & PCTK3 & PCTAIRE protein kinase 3 & 3.34 & 1368 \\
\hline$\underline{\cup 33053}$ & PKNI & protein kinase $\mathrm{NI}$ & 2.85 & 1075 \\
\hline$\underline{L 04270}$ & LTBR & lymphotoxin beta receptor (TNFR superfamily, member3) & 2.79 & 1406 \\
\hline$\underline{\cup 09579}$ & CDKNIA & cyclin-dependent kinase inhibitor IA (p2 I, Cipl) & 2.69 & 6193 \\
\hline$\underline{U 14966}$ & RPL5 & $60 S$ ribosomal protein L5 & 2.68 & $164 \mid$ \\
\hline M29039 & JUNB & jun-B & 2.65 & 1313 \\
\hline M2997I & MGMT & 6-O-methylguanine-DNA methyltransferase & 2.63 & 1971 \\
\hline M65199 & EDN2 & endothelin 2 & 2.58 & 1535 \\
\hline$\underline{\mathrm{U}} 57342$ & MLF2 & myeloid leukemia factor 2 & 2.52 & 2897 \\
\hline X69398 & CD47 & CD47 glycoprotein; integrin-associated protein & Up & 4152 \\
\hline$\underline{\mathrm{U}} 2255$ & FCGRT & Fc fragment of lgG, receptor, transporter & Up & 2960 \\
\hline AF004709 & MAPKI3 & mitogen-activated protein kinase 13 & Up & 2049 \\
\hline$\underline{X 02812}$ & TGFB & transforming growth factor, beta I & Up & 1535 \\
\hline$\underline{\mathrm{U}} 21092$ & TRAF3 & TNF receptor-associated factor 3 & Up & 1407 \\
\hline$\underline{U} 05875$ & IFNGR2 & interferon gamma receptor 2 & Up & 1372 \\
\hline$\underline{\times 67325}$ & IFI27 & interferon, alpha-inducible protein 27 & Up & 1182 \\
\hline 103909 & & gamma-interferon-inducible protein; IP-30 & Up & 1076 \\
\hline
\end{tabular}


Table 2: Down-regulated genes in HMTV env+ cells

\begin{tabular}{|c|c|c|c|c|}
\hline Acc \# & Gene symbol & Protein/gene & Ratio & Diff \\
\hline$\underline{U} 02687$ & FLT3 & fms-related tyrosine kinase 3 & -6.20 & -2143 \\
\hline$\underline{\times 74295}$ & IGA7B & integrin alpha 7B & -5.13 & -2249 \\
\hline$\times 53587$ & ITGB4 & integrin beta 4 & -4.80 & -2384 \\
\hline M3467I & CD59 & CD59 molecule, complement regulatory protein & -3.60 & -2551 \\
\hline$\underline{\mathrm{L} 2508 \mathrm{I}}$ & $\mathrm{RHOC}$ & ras homolog gene family, member $\mathrm{C}$ & -3.59 & -2341 \\
\hline$\underline{\mathrm{U} 89278}$ & $\mathrm{PHC} 2$ & polyhomeotic-like 2 & -3.53 & -1250 \\
\hline$\times 16277$ & ODCI & ornithine decarboxylase I & -2.87 & -1295 \\
\hline AF029670 & RAD5IC & RAD5I homolog C & -2.61 & -1713 \\
\hline M20430 & HLA-DRBI & MHC class II HLA-DR-beta & Down & -4288 \\
\hline j04III & JUN & c-jun proto-oncogene; transcription factor AP-I & Down & -1745 \\
\hline$\underline{\cup 70310}$ & FANCG & DNA repair protein $X R C C 9$ & Down & $-15 \mid 4$ \\
\hline M5991I & ITGA3 & integrin alpha 3 & Down & -1393 \\
\hline M97934 & STAT2 & signal transducer and activator of transcription 2 & Down & -1248 \\
\hline$\underline{\mathrm{L} 38518}$ & $\mathrm{SHH}$ & sonic hedgehog & Down & -1183 \\
\hline$\times 51521$ & VIL2 & ezrin; villin 2 & Down & -1177 \\
\hline$\underline{\mathrm{L} 07515}$ & $\mathrm{CB} \times 5$ & chromobox homolog 5; heterochromatin protein homolog I (HPI) & Down & -1153 \\
\hline MI5400 & RBI & retinoblastoma I & Down & -1109 \\
\hline M54995 & PPBP & pro-platelet basic protein & Down & -1100 \\
\hline$\times 54199$ & GART & trifunctional purine biosynthetic protein adenosine 3 & Down & -1092 \\
\hline$\underline{U} 47686$ & STAT5 A +B & signal transducer and activator of transcription $5 A+B$ & Down & -1072 \\
\hline
\end{tabular}

\section{Methods}

MCF-7 cells were obtained from American Type Culture Collection (ATCC) and were propagated in vitro as recommended by the provider and as described in previous publications $(1,5)$. To determine whether the viral protein was expressed in our MCF-7 cells, western blotting was used. Protein lysates were prepared from approximately $1 \times 10^{7}$ cells. Equal amounts of protein from each sample were loaded onto an SDS-PAGE-10\% polyacrylamide gel, followed by transfer to PVDF membranes. Western blot analysis was performed using mAbP2 (a monoclonal antibody against a peptide of the Env protein), and mAb-tubulin as primary antibodies (Sigma Aldrich). Proteins were visualized using horseradish peroxidase-labeled sheep anti-mouse IgG (GE Healthcare Bio-Sciences Corp.) as a secondary antibody followed by enhanced chemiluminescence (GE Healthcare Bio-Sciences Corp.).

The expression profile was studied using the Atlas Human Cancer 1.2 cDNA expression array; a nylon membrane printed with 200-600 bp long fragments of 1176 characterized genes involved in cancer, 9 housekeeping genes and 6 negative controls (Clontech, CA). These conditions were described in detail in a previous publication [25]. Briefly, RNA was extracted and labeled with Atlas pure total RNA labeling system and hybridized to an Atlas Human Cancer 1.2 cDNA expression array (Clontech, CA) according to the manufacturer's instructions. Both cell sublines were probed twice in separate assays, and the accuracy of each duplicate was assessed by Pearson's cor- relation coefficient based on the adjusted intensity of all genes spotted on the membrane.

Hybridizations with $30 \mu \mathrm{g}$ of total RNA were performed according to the manufacturer instructions. The hybridized membranes were exposed onto a phosphorimager screen and were read using a phosphorimager reader (Molecular Dynamics). The scanned images were aligned and analyzed using AtlasImage 2.01 software (Clontech). When averaging or comparing samples, the adjusted intensity signal was normalized using the global normalization mode featured in the software. We reported only those genes whose ratios of differential expression were 2.5-fold or more, or genes that were undefined for one type of sample, but were detected on the other. (Undefined genes are those whose intensity were below the signal threshold) In the later event, when we lack a numerical value for the ratio, it was defined as being "up" or "down". Furthermore, for each gene we stated the difference (diff) in adjusted normalized intensity between the two cell lines.

Accession number (Acc\#), gene symbol and protein or gene name are according to GeneBank.

\section{Acknowledgements}

Grant support: The T.J. Martell Foundation for Leukemia, Cancer and AIDS Research, The Jane Grinberg Memorial Fund, the Kash Family Foundation, and the Ellen Block Memorial Fund.

We thank Cindy Hernandez for skillful technical assistance and Jennifer Hasa and Julia Roboz for editorial work. 


\section{References}

I. Wang Y, Holland JF, Bleiweiss IK, Melana SM, Xu D, Pogo BGT: Detection of mammary tumor virus env gene-like sequences in human breast cancer. Cancer Res 1995, 55:5173-5179.

2. Etkind P, Du J, Khan A, Pillitteri J, Wiernik P: Mouse mammary tumor virus-like sequences in human breast tumors and in a lymphoma of a breast cancer patient. Cl Cancer Res 2000, 6:1273-1278.

3. Ford CE, Tran D, Deng YM, Ta VT, Rawlinson WD, Lawson JS: Mouse Mammary Tumor Virus-like gene sequences in breast tumors of Australian and Vietnamese women. Clin Cancer Res 2003, 9: I I 18-II20.

4. Zammarchi F, Pistello M, Piersiguilli X, Murr R, Di Cristofano C, Naccarato AG, Bevilacqua G: MMTV-like sequences in human breast cancer: a fluorescent PCR/laser microdissection approach. J Pathol 2006, 209:436-444.

5. Wang Y, Go V, Holland JF, Melana SM, Pogo BGT: Expression of MMTV-like env gene sequences in human breast cancer. $\mathrm{Cl}$ Cancer Res 1998, 4:2565-2568.

6. Melana SM, Holland JF, Pogo BGT: Search for MMTV-like env sequences in cancer and normal breast from the same individual. Cl Cancer Res 200I, 7:283-284.

7. Ford CE, Faedo M, Rawlinson WD: MMTV virus-like RNA transcripts and DNA found in affected cells of human breast cancer. Cl Cancer Res 2004, 10:7284-7289.

8. Liu B, Wang Y, Melana SM, Pelisson I, Najfeld V, Holland JF, Pogo BGT: Identification of a proviral structure in human breast cancer. Cancer Res 200I, 6 I:1754-1759.

9. Wang Y, Jiang JD, Xu D, Li Y, Holland JF, Qu C, Pogo BGT: A MMTV-like LTR superantigen in human breast cancer. Cancer Res 2004, 64:4105-4III.

10. Melana SM, Nepomnaschy I, Dales S, Rojowsky H, Abbott A, Jiang JD, Holland JF, Pogo BGT: A retrovirus in human berast cancer: Isolation and characterization of human mammary tumor virus [abstract]. Proc AACR 2006, 47: 1043.

II. Coussins LM, Werb Z: Inflammation and cancer. Nature 2002, 20:860-867.

12. Einav U, Tabach Y, Getz G, Ytzhaky A, Ozbek U, Amariglio A, Israelí $S$, Rechavi G, Domany E: Gene expression analysis reveals a strong signature of an interferon-induced pathway in childhood lymphoblastic leukemia as well as in breast and ovarian cancer. Oncogene 2005, 24:6367-6375.

13. McGrath CM, Grant PM, Soule HD, Glancy T, Rich MA: Replication of oncornavirus-like particle in human breast carcinoma cell line, MCF-7. Nature 1974, 252:247-250.

14. May EB, Westley BC: Characterization of sequences related to the mouse mammary tumor virus that are specific to MCF7 breast cancer cells. Cancer Res 1989, 49:3879-3883.

15. Bahia H, Ashman JNE, Cawkell L, Lind M, Monson JRT: Karyotypic variation between independently cultured strains of the cell line MCF-7 identified by multicolour fluorescence in situ hybridization. Int J Oncol 2002, 20:489-494.

16. Osborne CK, Hobbs K, Trent JM: Biological differences among MCF-7 human breast cancer 968 cell lines from different laboratories. Breast Cancer Res Treat 1987, 9:। II-I2I.

17. Nugoli M, Chuchana P, Vendrell J, Orsetti B, Ursule L: Genetic variability in MCF-7 sublines: evidence of rapid genomic and RNA expression profile modifications. BMC Cancer 2003, 3: I3.

18. Hiorns LR, Bradshaw TD, Skelton LA, Yu Q, Kelland LR, LeylandJones B: Variation in RNA expression and genomic DNA content acquired during cell culture. Brit J Cancer 2004, 90:476-482.

19. Wang Y, Pelisson I, Melana SM, Go V, Holland JF, Pogo BGT: MMTVlike env gene sequences in human breast cancer. Arch Virol 200I, 145:I-10.

20. Wang Y, Pelisson I, Melana SM, Holland JF, Pogo BGT: Detection of MMTV-like LTR and LTR-env gene sequences in human breast cancer. Int J Oncol 2001, I 8: I04I-1044.

21. Zangen R, Harden S, Cohen D, Parrella P, Sidransky D: Mouse mammary tumor-like env gene as a molecular marker for breast cancer. Int J Cancer 2002, I 02:304-307.

22. Soule HD, Vasquez J, Long A, Albert S, Brennan M: A human cell line from a pleural effusion derived from a breast carcinoma. J Nat Cancer Inst 1973, 5 I:1409-1416.

23. Pogo BGT, Melana SM, Holland JF, Mandeli JF, Piloti S, Casalini P, Ménard S: Sequences homologous to the MMTV env gene in human breast carcinoma correlate with overexpression of laminin receptor. Cl Cancer Res 1999, 5:2108-2III.

24. Wang Y, Melana SM, Baker B, Bleiweiss I, Fernandez-Cobo M, Mandeli J, Holland JF, Pogo BGT: Presence of MMTV-like env gene sequences in gestational breast cancer. Med Oncol 2003, 20:233-236.

25. Fernandez-Cobo M, Holland JF, Pogo BGT: Transcription profile of non-immortalized breast cancer cell lines. BMC Cancer 2006, 6(I):99.
Publish with Bio Med Central and every scientist can read your work free of charge

"BioMed Central will be the most significant development for disseminating the results of biomedical research in our lifetime. "

Sir Paul Nurse, Cancer Research UK

Your research papers will be:

- available free of charge to the entire biomedical community

- peer reviewed and published immediately upon acceptance

- cited in PubMed and archived on PubMed Central

- yours - you keep the copyright

Submit your manuscript here:

http://www.biomedcentral.com/info/publishing_adv.asp 